This item was submitted to Loughborough's Research Repository by the author.

Items in Figshare are protected by copyright, with all rights reserved, unless otherwise indicated.

\title{
Formation of Sn dendrites and SnAg eutectics in a SnAgCu solder
}

PLEASE CITE THE PUBLISHED VERSION

http://dx.doi.org/10.1016/j.scriptamat.2009.05.034

\section{PUBLISHER}

(c) Elsevier

VERSION

AM (Accepted Manuscript)

LICENCE

CC BY-NC-ND 4.0

REPOSITORY RECORD

Gong, Jicheng, Changqing Liu, Paul P. Conway, and Vadim V. Silberschmidt. 2019. "Formation of Sn Dendrites and Snag Eutectics in a Snagcu Solder". figshare. https://hdl.handle.net/2134/13467. 
This item was submitted to Loughborough's Institutional Repository (https://dspace.lboro.ac.uk/) by the author and is made available under the following Creative Commons Licence conditions.

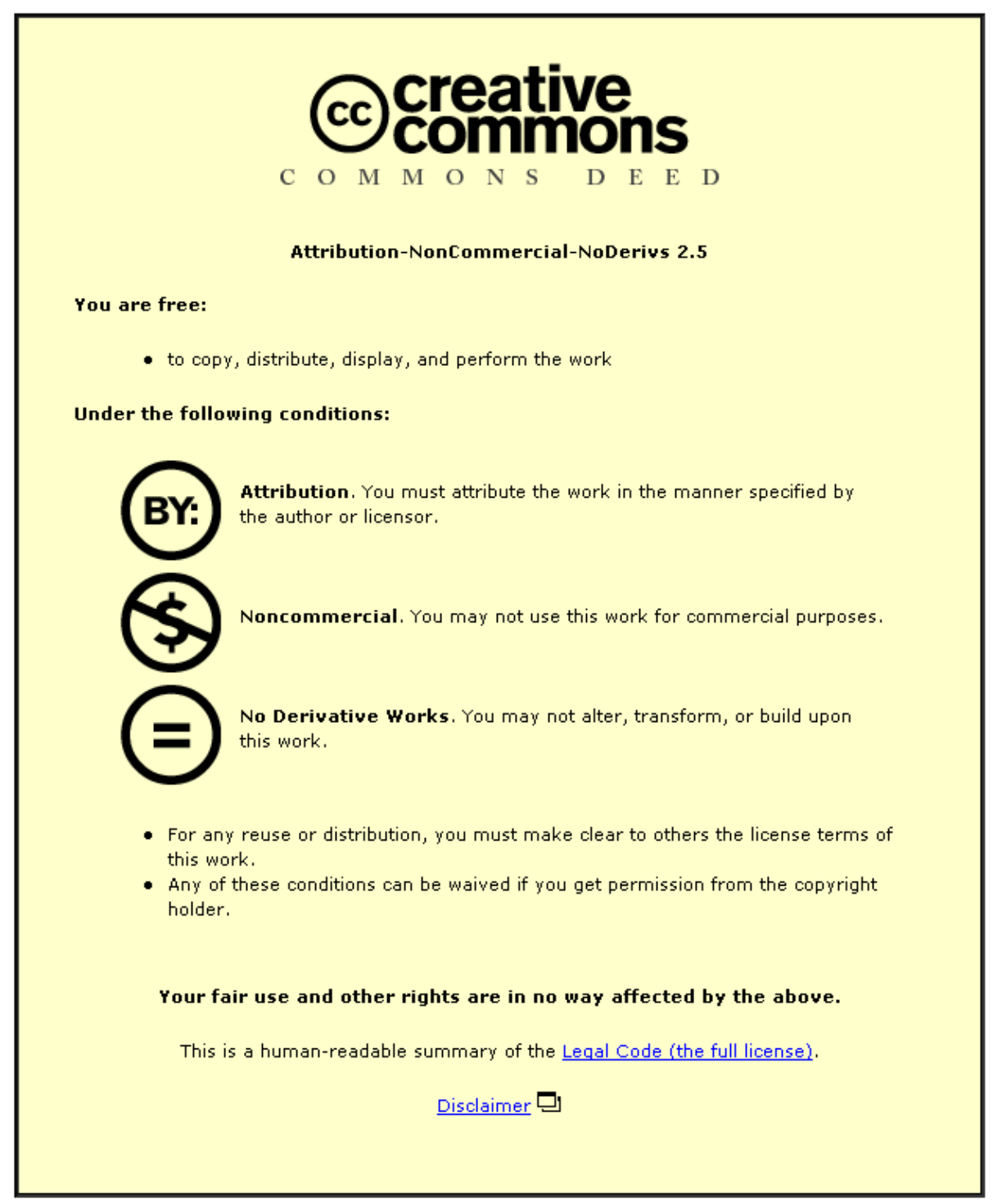

For the full text of this licence, please go to: http://creativecommons.org/licenses/by-nc-nd/2.5/ 


\title{
Formation of Sn Dendrites and SnAg Eutectics in a $\mathrm{SnAgCu}$
}

\section{Solder}

\author{
Jicheng Gong ${ }^{\mathrm{a}}$, Changqing Liu ${ }^{\mathrm{b}}$, Paul P. Conway ${ }^{\mathrm{b}}$, Vadim V. Silberschmidt ${ }^{\mathrm{b}}$ \\ ${ }^{\mathrm{a}}$ Department of Materials, University of Oxford, Parks Road, Oxford, OX1 3PH, UK \\ ${ }^{\mathrm{b}}$ Wolfson School of Mechanical and Manufacturing Engineering \\ Loughborough University, Loughborough, LE11 3TU, UK
}

The formation behaviour of grains and their components, including Sn dendrites, $\mathrm{Cu}_{6} \mathrm{Sn}_{5}$ and $\mathrm{Ag}_{3} \mathrm{Sn}$ intermetallic compounds (IMCs), in a $\mathrm{SnAgCu}$ alloy is investigated in an experiment, capable to obtain the solid reactants directly from the liquid solder during the liquid-to-solid phase transformation. The results show that $\mathrm{Cu}_{6} \mathrm{Sn}_{5}$ IMCs are formed first in a grain; then large Sn dendrites; fibre-like $\mathrm{Ag}_{3} \mathrm{Sn}$ IMCs are formed ahead of the $\beta$-Sn matrix in the coupling process generating eutectics.

Key words: soldering; eutectic solidification; dendrite growth; intermetallics

In the eutectic $\mathrm{SnAgCu}$ alloy, one of the most promising $\mathrm{Pb}$-free candidates for solder interconnections in electronic packages, the main components are $\mathrm{Ag}_{3} \mathrm{Sn}, \mathrm{Cu}_{6} \mathrm{Sn}_{5}$ IMCs and $\beta$-Sn. Under equilibrium solidification, $\mathrm{Ag}_{3} \mathrm{Sn}$ and $\mathrm{Cu}_{6} \mathrm{Sn}_{5} \mathrm{IMCs}$ are formed in the $\beta$-Sn matrix, leading to a uniform eutectic microstructure. However, this alloy system usually deviates from the eutectic transformation in manufacturing processes, e.g., due to a relatively high cooling rate. In most cases, large amounts of soft Sn 
dendrites are generated in a grain [1-4]. Sometimes, large brittle $\mathrm{Ag}_{3} \mathrm{Sn}$ plates, which can stretch across the entire joint, are found [5]. The formation behaviour of these microstructural components is important, since the size of solder joints has been miniaturized to the same scale as that of grains: a joint contains only one or a few grains [6-9]. Considering the relatively large size and the anisotropic characteristics, the character of a grain plays an important role in a small joint's performance. Recent works have demonstrated this influence on both the mechanical $[10,11]$ and electrical behaviour [12] of some Sn-based solders. To optimize the microstructure of a solder joint with a few grains, better understanding of the formation behaviour of main phases and IMCs in solder materials at the grain or sub-grain level is required. This paper investigates the microstructure that is formed in $\mathrm{SnAgCu}$ solder bumps during solidification. Basic components, including $\beta$-Sn dendrites, $\mathrm{Ag}_{3} \mathrm{Sn}, \mathrm{Cu}_{6} \mathrm{Sn}_{5} \mathrm{IMCs}$ in eutectics and the $\beta$-Sn matrix, were studied to present a whole process of formation of a $\mathrm{SnAgCu}$ grain.

Due to the absence of solid-state phase transformations in the $\mathrm{SnAgCu}$ eutectic alloy from the melting point to room temperature, its microstructure is mainly determined by the liquid-to-solid transformation. The experiments were specially designed to obtain the solid reactants out of the liquid solder during reflow. Details of the set-up were present in [13]. In experiments, a circle printed circuit board (PCB) specimen with $\mathrm{Cu}$ pads (the solder material is placed on these pads) on the edge, is fixed to a spindle placed in an oven. The distance between the centre of PCB specimen and a bump is 5 $\mathrm{mm}$. The temperature of solder bumps of the specimen is continuously monitored during reflow. When the solder bump reaches a specific temperature, spinning of the spindle is triggered with the rotation rate of $10000 \mathrm{rpm}$.. Still-liquid parts of the solder 
are removed from the $\mathrm{Cu}$ pads due to the centrifugal force, leaving there only solid reactants. The rotation rate is chose based on the criteria that it is high enough to remove quickly the remaining liquid from solid reactant, while it still causes no mechanical deformation on the solid reactants. By a series of these spinning tests at different stages of solidification, the whole process of formation of solid reactants out of the liquid phase can be presented. The solder material used in this study is a commercial Sn3.8Ag0.7Cu paste, containing $13 \%$ flux by weight. Fig. 1a presents the pre-designed temperature profiles for the tests; Fig. 1b demonstrates an enlarged portion of the curve in Fig. 1a for the cooling stage.

When solidification occurs in a solder bump, the temperature increases at the cooling stage, as shown in Fig. 1b, due to the released heat. The change in temperature corresponds to the whole process of solidification: the moment that the temperature increases indicates its start; the drop in temperature shows that the transformation is close to the end. A spinning test is conducted at the beginning of the heat release (Point A in Fig. 1b); the respective image is given in Fig. 2a. It shows that there is an oxidized layer on the surface of the bump, and a part of this layer is broken. Under this oxidized layer, a large amount of Sn dendrites is distributed inside the bump, indicating a semisolidified stage of the process. Obviously, the space between dendrites before spinning is filled with the liquid solder, which is removed from the bump through the broken oxidized layer. The results show that Sn dendrites are formed earlier that the Sn matrix in eutectics: once $\beta$-Sn is nucleated, it grows quickly, forming large-size dendrites. Considering the fact that the lattice of a Sn dendrite is consistent with that of the $\beta$-Sn matrix of adjacent eutectics $[1,6]$, it is suggested that the $\mathrm{Sn}$ matrix in $\mathrm{SnAgCu}$ eutectics is formed from the existing $\mathrm{Sn}$ dendrites, and retains the same lattice 
orientation. In this case, the size of $\mathrm{Sn}$ grains is predominantly controlled by the formation behaviour of $\mathrm{Sn}$ dendrites. Figure $2 \mathrm{~b}$ shows that the size of an individual $\mathrm{Sn}$ dendrite can reach several hundreds micrometers. This phenomenon explains the fact that a $\mathrm{SnAgCu}$ grain can have such a large size, and a solder joint contains only a few grains. The consistent lattice of $\mathrm{Sn}$ dendrites and the $\beta$-Sn matrix means that the orientation of Sn grains is determined by that of the initial dendrites at the nucleation stage. Figure $2 \mathrm{c}$ captures some dendrites at such a stage. It shows that some $\mathrm{Sn}$ dendrites are nucleated on the oxidized layer. This heterogeneous nucleation requires a lower energy and leads to relatively low undercooling (about $10 \mathrm{~K}$ ).

To further investigate parameters of $\mathrm{Sn}$ dendrites, one of them is selected and focused on (Fig. 2b). The figure demonstrates that the size of the dendrite is large (more than $500 \mu \mathrm{m})$ in the longitudinal direction, which is considered as the major growth direction. In this direction, the dendrite can be divided into two parts according to its diameter: the main body of the dendrite and the tip. In the main body, there is a long spine in the centre along the dendrite's major growth direction, the diameter of which is about $50 \mu \mathrm{m}$. In the direction normal to the spine, secondary arms grow from the spine. The size of secondary arms varies; the ratio of primary to secondary arms is approx. 3 . However, some of them seem to grow in the same direction as seen in Fig. $2 b$ for secondary arms 1 to 11 . The spacing between secondary arms is approx. $30 \mu \mathrm{m}$. With respect to the tip of the dendrite, its diameter (normal to the major growth direction) reduces gradually and finally ends in a sharp tip as shown in Fig. 2a. An interesting observation is that the tip does not grow straightforward but turns sideward. Looking at the entire bump in Fig. 2a, it is obvious that the front tip is close to the surface of the bump. It is suggested that the growth of the Sn dendrite is limited by the boundary of 
the bump. In other words, the morphology of a bump, e.g., its shape and size, can influence the growth behaviour of dendrites. To correlate the growth behaviour and the internal lattice orientation, a slice is lifted out of the tip of a dendrite, as shown in Figs. 2d, e and $\mathrm{f}$, for transmission electron microscopy (TEM) analysis. The diffraction pattern and energy-dispersive X-ray (EDX) analysis on TEM confirms that the investigated structure is a single crystal of $\beta$-Sn. The diffraction pattern also shows that the [110] direction is close to the preferable growth orientation of the investigated Sn dendrite.

To study the subsequent phase transformation, a bump is tested at Point B (shown in Fig. 1b), which is close to the end of the temperature increase stage; Fig. 3a presents the solder on the bump. It can be seen that most of the bump has became solid, indicating that the solidification is close to the end. Figure $3 \mathrm{~b}$ presents a local area of Fig. 3a; it shows that dendrites are extruded from the relatively flat surfaces. These relatively flat surfaces at the bottom of, or between, dendrites are undergoing active growth at this moment. Comparing with the microstructure of a fully solidified solder and considering relative locations of each component, these surfaces reflect the growth behaviour of $\mathrm{SnAgCu}$ eutectics; they are the interface between eutectics and the liquid solder. Figure $3 \mathrm{c}$ focuses on a local area of these surfaces. It can be seen that the eutectics/liquid interface is not flat at the micro scale. A large amount of micro cusps is spread over it, with their tips extruding towards the liquid. A diffraction pattern with EDX on TEM shows that these needles are $\mathrm{Ag}_{3} \mathrm{Sn}$ IMCs. This indicates that $\mathrm{Ag}_{3} \mathrm{Sn}$ IMCs are formed ahead of the Sn matrix in the coupling process, generating eutectics. To investigate the growth behaviour of these $\mathrm{Ag}_{3} \mathrm{Sn}$ IMCs, a cross-section is prepared on the surface of eutectics as shown in Fig. 4b. It can be seen that $\mathrm{Ag}_{3} \mathrm{Sn}$ has fibre morphology in the $\mathrm{Sn}$ 
matrix, with the longitudinal direction of fibres close to the normal to the solid/liquid interface. The axial direction is the preferable growth orientation of these fibres. To characterize these $\mathrm{Ag}_{3} \mathrm{Sn}$ fibres, a fully solidified specimen is prepared with deep etching. By removing Sn dendrites and the $\mathrm{Sn}$ matrix, $\mathrm{Ag}_{3} \mathrm{Sn}$ fibres in eutectics are presented as shown in Fig. 4c. It can be seen that the length of these $\mathrm{Ag}_{3} \mathrm{Sn}$ fibres can be more than $100 \mu \mathrm{m}$, and that they are orderly distributed: these fibres are orientated nearly in the same direction. To explore the formation behaviour with this regularity, a TEM specimen is prepared on the cross-section in Fig. $4 \mathrm{~b}$ and presented in Fig. 4d. Diffraction analysis is performed on the TEM specimen. It confirms that an individual $\mathrm{Ag}_{3} \mathrm{Sn}$ fiber is a single crystal by achieving the same diffraction pattern at different sites of one fiber. It is also found that all the analyzed $\mathrm{Ag}_{3} \mathrm{Sn}$ fibres have a similar lattice orientation. A further analysis shows that the lattice orientation of $\mathrm{Ag}_{3} \mathrm{Sn}$ fibres have some relation to that of the $\beta$-Sn matrix as demonstrated by diffraction patterns in Figs. 4d, e and f: plane (02-1) and direction [-112] in $\mathrm{Ag}_{3} \mathrm{Sn}$ fibres have the same orientation as that of plane (001) and direction [011] in the $\beta$-Sn matrix, respectively. The index in Fig. $4 \mathrm{~g}$ also shows that the axial direction of the preferable growth of $\mathrm{Ag}_{3} \mathrm{Sn}$ fibres is close to the one, normal to the plane (02-1).

The same orientation of different $\mathrm{Ag}_{3} \mathrm{Sn}$ fibres could result from their nucleation behaviour: the obtained $\mathrm{Ag}_{3} \mathrm{Sn} / \beta-\mathrm{Sn}$ lattice pair may have the lowest interfacial energy; $\mathrm{Ag}_{3} \mathrm{Sn}$ fibres are nucleated based on the same existing $\mathrm{Sn}$ dendrites or matrix with this interface, resulting in the same lattice orientation. Since $\mathrm{Ag}_{3} \mathrm{Sn}$ IMCs are formed ahead of the $\beta$-Sn matrix, their growth predominantly determines the movement of the eutectics/liquid interface. When two eutectics/liquid interfaces from different grains meet each other, a grain boundary is formed. Figure 4a captures the formation 
behaviour of such grain boundary. At this moment, the formation of the grain is close to the end.

Some $\mathrm{Cu}_{6} \mathrm{Sn}_{5}$ IMCs are found to form prior to $\mathrm{Sn}$ dendrites, having the morphology of long needles. Figures $2 \mathrm{a}$ and $\mathrm{b}$ present some of these $\mathrm{Cu}_{6} \mathrm{Sn}_{5}$ IMCs. During reflow, the $\mathrm{Cu}$ substrate dissolves into the liquid solder. According to the concept of the local nominal composition (LNC) [14], the ratio of $\mathrm{Ag}$ to $\mathrm{Sn}$ composition is constant in the bump. The $\mathrm{Cu}$ composition is higher when the local site is closer to the substrate. In some locations, e.g. near the substrate, the LNC could be in the $\mathrm{Cu}_{6} \mathrm{Sn}_{5}$ region in the phase diagram as shown in [9]. In this case, $\mathrm{Cu}_{6} \mathrm{Sn}_{5}$ IMCs are the primary phase during solidification. Since these IMCs are formed earlier, sometimes they are encircled by Sn dendrites.

In summary, this paper studies the formation behaviour of a grain in $\mathrm{SnAgCu}$ solder bumps during solidification. The results show that: $\mathrm{Cu}_{6} \mathrm{Sn}_{5}$ IMCs are formed first among the investigated reactants. They have the cusps-like morphology, and can be embedded in Sn dendrites. Sn dendrites are generated earlier than the Sn matrix in $\mathrm{SnAgCu}$ eutectic. Their lattice determines the orientation of the final Sn-phase in the grain. The size of a Sn dendrite can reach hundreds of micro-metres, which predominantly determines the large size of a $\mathrm{SnAgCu}$ grain. Eutectics are formed after, and from, Sn dendrites. In eutectics, $\mathrm{Ag}_{3} \mathrm{Sn}$ IMCs have morphology of long fibres. They are formed ahead of the Sn matrix in the coupling process to generate eutectics. In addition, $\mathrm{Ag}_{3} \mathrm{Sn}$ fibres in eutectics have the same crystal orientation; their lattice is coupled with that of the Sn matrix.

\section{Acknowledgements}


The work is financially supported by the Engineering and Physical Sciences Research Council's Innovative Manufacturing and Construction Research Centre at Loughborough University, UK under GR/R64483/01P.

\section{References}

[1] A. LaLonde, D. Emelander, J. Jeannette, C. Larson, W. Rietz, D. Swenson, D.W. Henderson, J. Electron. Mater. 33 (2004) 1545.

[2] R.H. Mathiesen, L. Arnberg, F. Mo, T. Weitkamp, A. Snigirev, Phys. Rev. Lett. 83 (1999) 5062.

[3] B. Li, H.D. Brody, A. Kazimirov, Phys. Rev. E. 70 (2004) 062602.

[4] R. Kinyanjui, L.P. Lehman, L. Zavalij, E. Cotts, J. Mater. Res. 20 (2005) 2914.

[5] K. Zeng, K.N. Tu, Mat. Sci. Eng. R 38 (2002) 55.

[6] D.W. Henderson, J.J. Woods, T.A. Gosselin, J. Bartelo, J. Mater. Res. 19 (2004) 1608.

[7] A.U. Telang, T.R. Bieler, S. Choi, K.N. Subranmanian, J. Mater. Res. 17 (2002) 2294.

[8] A.U. Telang, T.R. Bieler, Scripta. Mater. 52 (2005) 1027.

[9] T. Mattila, V. Vuorinen, J.K. Kivilahti, J. Mater. Res. 19 (2004) 3214.

[10] M.A. Matin, E.W.C. Coenen, W.P. Vellinga, M.G.D. Geers, Scripta. Mater. 53

927.

[11] A.U. Telang, T.R. Bieler, A. Zamiri, F. Pourboghrat, Acta. Mater. 55 (2007) 2265

[12] M. Lu, D. Shih, P. Lauro, C. Goldsmith, D.W. Henderson, Appl. Phys. Lett. 92 (2008) 211909.

[13] J. Gong, C. Liu, P.P. Conway, V.V. Silberschmidt, Acta. Mater. 56 (2008) 56 4291. 
[14] K. Rönkä, F. J. J. van Loo, J.K. Kivilahti, Scr. Mater. 37 (1997) 1575.

\section{Figure Captions}

Fig. 1 (a) Temperature profiles during reflow. The cooling rate is $30 \mathrm{~K} / \mathrm{min}$. (b) Cooling stage of the curve 1 in (a).

Fig. 2 Sn dendrites formed in a $\mathrm{Sn} 3.8 \mathrm{Ag} 0.7 \mathrm{Cu}$ solder bump at Point A in Fig. 1b: (a) entire bump; (b) local area; (c) nucleation of Sn dendrites on the inner surface of the oxidized layer. A tip of the $\beta$-Sn dendrites: (d) large area; (e) local area; (g) TEM image and diffraction pattern of the tip.

Fig. $3 \mathrm{Sn}$ dendrites and $\mathrm{SnAgCu}$ eutectics formed in a $\mathrm{Sn3} .8 \mathrm{Ag} 0.7 \mathrm{Cu}$ solder bump at Point B in Fig. 1b: (a) entire bump; (b) local area of a specimen; (c) surface of eutectics. Fig. $4 \mathrm{SnAgCu}$ eutectics and grain boundaries formed in a $\mathrm{Sn} 3.8 \mathrm{Ag} 0.7 \mathrm{Cu}$ solder bump at Point B in Fig. 1b: (a) large area; (b) cross section on the surface of eutectics; (c) $\mathrm{Ag}_{3} \mathrm{Sn}$ fibres formed in $\mathrm{SnAgCu}$ eutectics of a fully solidified bump (this specimen is prepared by deep etching); (d) TEM image of a specimen, which is prepared on the cross-section in (b); diffraction pattern on the $\beta$-Sn matrix (e), $\mathrm{Ag}_{3} \mathrm{Sn} \mathrm{IMCs}(\mathrm{f})$ and $\beta$ $\mathrm{Sn} / \mathrm{Ag}_{3} \mathrm{Sn}$ interface (g). 


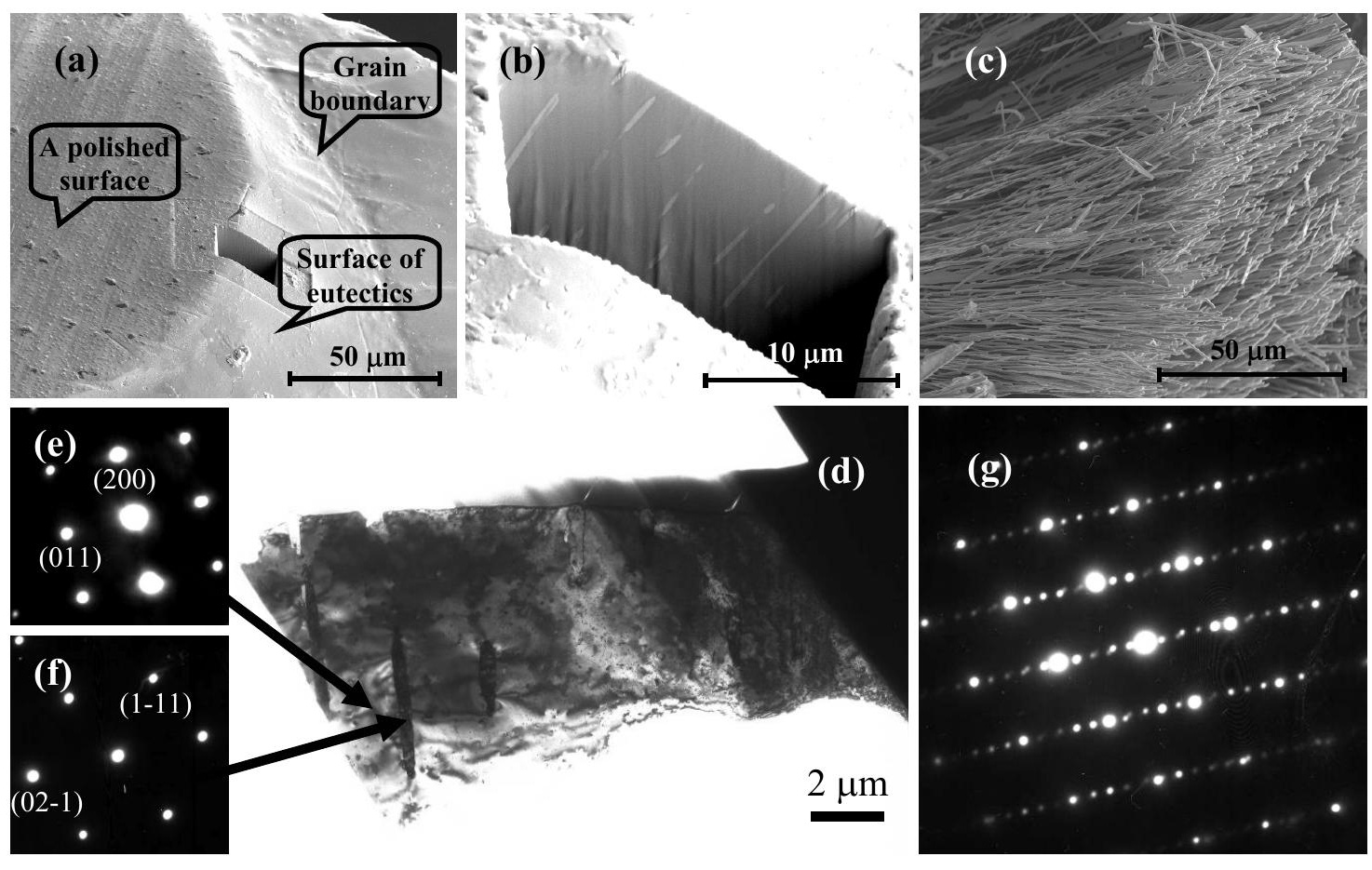


(a)
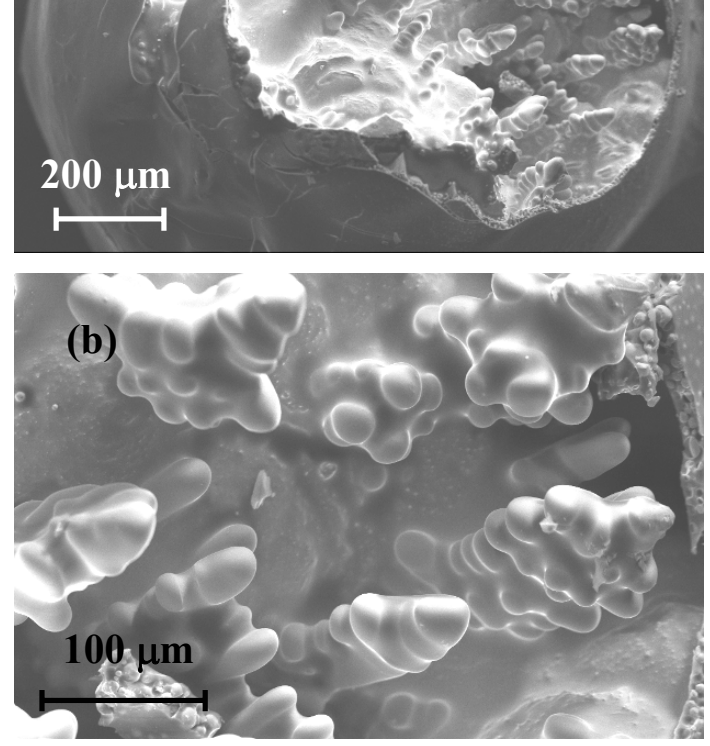

(c)

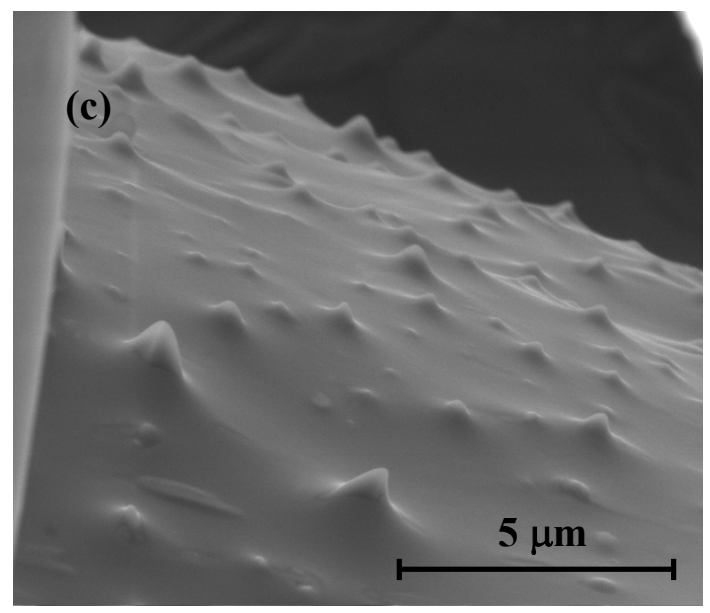




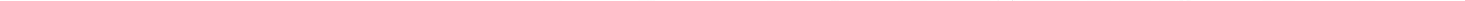



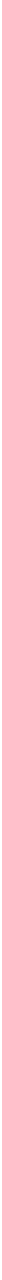